\title{
Obstetrical Vacuum Deliveries: Clinical Aspects and Fetal Prognosis in Regional Teaching Hospital of Ouahigouya
}

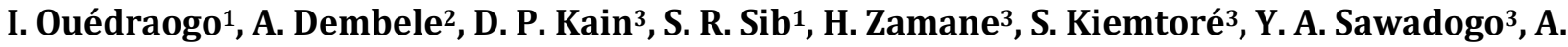 \\ Ouattara $^{3}$, S. Y. Kaboré ${ }^{4}$, D. Sourgou ${ }^{1}$, B. Tieba-Bonané ${ }^{3}$
}

${ }^{1}$ Regional Teaching Hospital of Ouahigouya, Ouahigouya, Burkina Faso

${ }^{2}$ Sourou Sanon Teaching Hospital, Bobo-dioulasso, Burkina Faso

${ }^{3}$ Yalgado OUEDRAOGO Teaching Hospital, Ouagadougou, Burkina Faso

${ }^{4}$ Regional Hospital of Tenkodogo, Tenkodogo, Burkina Faso

Email: oued_issa@yahoo.fr

How to cite this paper: Ouédraogo, I., Dembele, A., Kain, D.P., Sib, S.R., Zamane, H., Kiemtoré, S., Sawadogo, Y.A., Ouattara, A., Kaboré, S.Y., Sourgou, D. and TiebaBonané, B. (2018) Obstetrical Vacuum Deliveries: Clinical Aspects and Fetal Prognosis in Regional Teaching Hospital of Ouahigouya. Open Journal of Obstetrics and Gynecology, 8, 122-129.

https://doi.org/10.4236/ojog.2018.82016

Received: December 20, 2017

Accepted: February 6, 2018

Published: February 9, 2018

Copyright $\odot 2018$ by authors and Scientific Research Publishing Inc. This work is licensed under the Creative Commons Attribution International License (CC BY 4.0).

http://creativecommons.org/licenses/by/4.0/ (c) (i) Open Access

\begin{abstract}
Objective: To determine the frequency of obstetrical vacuum deliveries in the service of obstetrics and gynecology of regional teaching hospital of Ouahigouya and then to assess fetal outcomes. Patients and Methods: It was about a cross sectional and descriptive retrospective data collection from $1^{\text {st }}$ January 2014 to $31^{\text {st }}$ December 2016 in the service of obstetrics and gynecology of regional teaching hospital of Ouahigouya. Patients who had vacuum delivered in the service with single pregnancy, at least 34 weeks gestation age and summit presentation and had a useful medical folder were included in our study. The data were collected and the analysis used epi-info software 7.2.1.0. version, 2010 Word and excel. The results were presented in percentage for qualitative variables and in means standard deviation for quantitative variables. Results: We have collected 6233 deliveries from $1^{\text {st }}$ January 2014 to $31^{\text {st }}$ December 2016, out of which 312 were done by using obstetrical vacuum giving a frequency of $5.0 \%$. The mean age of patients was $23.5 \pm 6.4$ years. The average parity was $1.3 \pm 0.7$ women per delivery and $73.1 \%$ of our patients were pauciparous. $90.1 \%$ of patients were referred. The main indications were maternal weakness (43\%), fetal distress (36.5\%), prolonged expulsive phase (6.1\%), stopping progression (4.8\%) and the scar uterus (4.5\%). Fetal prognosis was dominated by the caput in 13 cases $(4.2 \%)$ and excoriations of the scalp in 5 cases (1.7\%). Conclusion: Vacuum extractions are very limited in low setting countries. Its popularization is essential to reduce maternal and fetal mortality.
\end{abstract}




\section{Keywords}

Obstetrical Vacuum, Frequency, Indications, Fetal Prognosis

\section{Introduction}

Instrumental extraction is a vaginal delivery assistance using an adapted tool: vacuum, Forceps or spatula. Vacuum is an extraction appliance, the most used in Africa and Asia [1]. The rates of deliveries by vacuum use vary from $2 \%$ to $10 \%$ [2]. Hospital studies show rates low than 2\% [3] [4] [5] [6].

In Burkina Faso, in 2010, an assessment of emergency obstetrical care providing had concluded that vacuum extractions were not widely used [7].

Our study would help to appreciate the advantage of this instrument in the maternity of the Regional Teaching Hospital of Ouahigouya and its contribution of the quality in term of care of patients.

\section{Patients and Methods}

We conducted a cross-sectional study for descriptive purposes including a retrospective data collection from $1^{\text {st }}$ January 2014 to $31^{\text {st }}$ December 2016 in the service of obstetrics and gynecology of regional teaching hospital of Ouahigouya (RTHO).

The RTHO is the referral center of six sanitary districts of the North Region which are: Ouahigouya, Titao, Thiou, Seguenega, Gourcy and Yako. Its population zone of cover is estimated of 1.587 .866 inhabitants in 2017 (General Census of Population and Housing 2006).

Were included in our study, all patients who have had a vacuum delivery in the service with single pregnancy at least 34 weeks gestation, with summit presentation and having a useful medical folder.

Have not been included women who have had a vacuum delivery and having an unusable medical folder.

Variables used were socio-demographical characteristic (age, parity, living place), clinical characteristic (mode of admission, gestational age, fetal heart rate, amniotic liquor aspect, status pelvis, level of engagement of presentation), Indications of vacuum use and fetal outcomes.

The collect of data were done using a questionnaire pre-tested. It included patient identity, clinical characteristics, procedure of the use of vacuum and maternal and neonatal outcomes.

The data were collected and analysis using epi-info software 7.2.1.0. version 2010 Word and Excel. The results were presented in percentage for qualitative variables and in means standard deviation for quantitative variables.

\section{Ethics Approval}

This study was conducted under the supervision of THE UNIVERSITY OUAGA I 
PROFESSOR JOSEPH ZERBO KY, medical school. We obtained the approval of the Medical Establishment Commission of regional teaching hospital of Ouahigouya which acts as an ethics committee at the local level. Confidentiality of individual data was ensured at all stages of the study, during the collection and analysis of data through the use of individual and anonymous data collection forms.

\section{Results}

\subsection{Frequency}

We have collected 6233 deliveries during the period of study, out of which 312 have needed obstetrical vacuum use giving a frequency of 5.0\%; 1863 Cesarean-sections (29.9\%) and 4058 (65.1\%) vaginal deliveries.

\subsection{Sociodemographical Variables}

The mean age of patients was $23.5 \pm 6.4$ with range of 14 and 40 years; 115 parturiantes $(36.9 \%)$ were less than 20 years. The mean parity was $1.3 \pm 0.7$ and the highest one was 9; the nulliparous women were 182 (58.3\%). The women without non-salary occupation (housewives and pupils) represented 90.1\% (281); 203 (97.1\%) were married or cohabitation status. The refereed patients were 220 $(70.5 \%)$.

\subsection{Clinical Variables}

\section{-Gestational age}

Patients whose term was greater than or equal to 37 weeks of amenorrhea were three hundred six (309) or $99 \%$ and 3 patients, or $1 \%$ had a term is between 34 and 37 weeks of amenorrhea.

\section{-Fetal heart rate}

Before the application of the Obstetric vacuum, 265 patients, or $85.5 \%$ had a fetal heart rate between 120 and 160 beats/minute; 19 patients, $6.1 \%$, had a fetal heart rate of less than 120 beats/minute; 13 patients, $4.2 \%$, had a fetal heart rate greater than or equal to 160 beats/minute. Fetal heart rate was not seen at obstetrical stethoscope of Pinard in 13 patients, $4.2 \%$ of cases.

\section{-Amniotic liquor aspect}

According to the aspect of amniotic fluid, in 177 patients (56.7\%) it was clear liquor, in 64 cases $(20.5 \%)$ it was meconium stained liquor patients and 3 patients (1\%) had mash pea liquor.

\section{-Pelvic status}

The internal pelvimetry revealed that 300 parturients, $96.2 \%$ had a clinically normal pelvis, $8,2.5 \%$ had a limited pelvis and $4,1.3 \%$ and asymmetric pelvis.

\section{-Level of presentation}

The obstetrical vacuum was applied to the lower strait in $72.1 \%$.

The level of the descent of the presentation was not appreciated in 69 cases (Table 1).

-Indications of obstetrical vacuum 
The indication of the suction cup was not specified in 19 cases (Table 2).

\subsection{Neonatal prognosis}

\section{- Status of Newborns at birth}

The use of obstetrical vacuum has allowed getting 286 alive newborns, $91.7 \%$. The distribution of the status of newborns is presented in Table 3.

\section{- Neonatal complications}

In our study, 18 neonates had a complication at a frequency of $5.9 \%$. The neonatal complications observed were caput in 13 cases (4.2\%) and excoriations of the scalp in 5 cases (1.7\%).

Table 1. Distribution of patients by level of presentation of the fetal head $(n=243)$.

\begin{tabular}{ccc}
\hline level of presentation & Absolute value & Percentage (\%) \\
\hline Lower strait & 225 & 92.6 \\
Mean strait & 16 & 6.6 \\
Higher strait & 2 & 0.8 \\
Total & 243 & 100 \\
\hline
\end{tabular}

Table 2. Distribution of the patients according to the indications of obstetrical vacuum use $(n=293)$.

\begin{tabular}{ccc}
\hline Indications of obstetrical vacuum use & Number & Percentage (\%) \\
\hline Maternal weakness & 126 & 43 \\
Fetal distress & 107 & 36.5 \\
Prolonged second stage of labor & 18 & 6.1 \\
Non progress of fetal head & 14 & 4.8 \\
One previous uterine scar & 13 & 4.5 \\
Maternal disease & 8 & 2.7 \\
Refusal to push & 7 & 2.4 \\
Total & 293 & 100 \\
\hline
\end{tabular}

Table 3. Distribution of parturients according to the condition of the newborn at birth.

\begin{tabular}{|c|c|c|}
\hline Parameters of newborns & Number & Percentage (\%) \\
\hline Not resuscitated & 204 & 65.4 \\
\hline Resuscitated & 82 & 26.3 \\
\hline Still birth & 26 & 8.3 \\
\hline APGAR score less than 7 at $1^{\text {st }}$ minute & 114 & 36.5 \\
\hline APGAR score less than 7 at $5^{\text {th }}$ minute & 69 & 22.1 \\
\hline APGAR score $\geq 7$ at the $5^{\text {th }} \mathrm{min}$ & 247 & 77.9 \\
\hline
\end{tabular}




\section{Discussion}

\subsection{Limitations and Constraints}

This study was conducted in the service of obstetrics and gynecology of regional teaching hospital of Ouahigouya.

-The fact that it is retrospective study has leaded to limitations by:

-The loss of some of clinical folders;

-The insufficiency of information in some of clinical folders;

-The non-full complete information of important items in some of clinical folder like level of education, the data of anthropometric parameters.

\subsection{Frequency}

The rate of extraction is $5.01 \%$ in our study. It is comparable to those of Raynal $\mathrm{P}$, et al. in French Guyane [8], of Dupuis $\mathrm{O}$ et al. [9] in France and Boni S et al. [10] in Ivory Coast who have found respectively $4.35 \%, 4.9 \%$ and $5.95 \%$.

Our rate is higher very than to that observed by Mutombo K L; et al. in Congo [4], Randriambololona D M A. et al. in Madagascar, Cisse C T et al. in Senegal [3], Ouattra S et al. in Burkina Faso [11], Nolens B et al. in Ouganda [5] and Traore $\mathrm{M}$ et al. in Mali [12] who have found respectively $0.4 \%, 1.27 \%, 1.38 \%$, $1.85 \%, 2.4 \%$ and $3.7 \%$. Many reasons would explain that high rate of extraction by vacuum in our study: the obstetrical vacuum is used by midwives as well as doctors and the obstetrical vacuum is the only instrument available in our service unlike other authors who use forceps or spatula in addition to vacuum. Otherwise, once the indication of extraction is posed, the best instrument is the one to which the operator is most accustomed.

\subsection{Indication of Vacuum Use}

The main indications of the use of vacuum in our study were most represented by maternal weakness (43\%), fetal distress (36.5\%), prolonged expulsive phase (6.1\%), stopping progression (4.8\%) and the scar uterus (4.5\%). Those indications are widely reported by many authors:

-Ouattara S et al. in Burkina Faso [11] has reported 46.72\%, 24.29\% and 8\% respectively for poor expulsive efforts, maternal weakness and fetal distress.

-Traore B et al. in Mali [13] has found 10.3\% for poor expulsive efforts and $5.7 \%$ for fetal distress.

-Cisse C $\mathrm{T}$ et al. in Senegal [3] has reported: $32.9 \%$ for maternal weakness, $24.9 \%$ for uterine scar and $21.4 \%$ for fetal distress.

Grisot C [14], in a comparative study of the perineal morbidity of extractions by spatulas and by vacuum, found for its part a predominance of the indications for insufficient expulsive efforts and acute fetal distress respectively in the proportions $44.8 \%$ and $53.7 \%$.

While other author have found that fetal distress was the first indication of vacuum use [15] [16] [17]. 


\subsection{Fetal Prognosis}

In our series, most of newborns were alive (91.7\%) versus $8.3 \%$ of fresh still birth.

At the first minute, the Apgar score was less than 7 in $36.50 \%$ of babies versus $22.1 \%$ at the fifth minute.

Neonatal deaths rate in our study was high compared to what is reported in literature. Indeed, Ouattara S et al. in Burkina Faso [11], Randriambololona DMA et al. in Madagascar [6] and Cisse C T et al. in Senegal [3] have reported respectively $1.87 \%, 4.38 \%$ and $6 \%$.

Our rate is certainly biased because of pre-existing fetal over-morbidity: hypoxia or infection. Obstetrical vacuum may add its own complications. In that situation, instrumental extraction is often carried out in order to hasten the exit of the fetus from an harmful environment which is no longer profitable for him and for which a caesarean decision would be taken too late because there would be a risk of imminent perinatal death.

Regarding to the neonatal morbidity aspects we have observed 5.9\% of complications. The main complication were caput succedaneum (4.2\%) and head excoriations $(1.7 \%)$. There was no case of major complications like fractures of the skull, intra skull hemorrhage and skull-hematoma.

Because instrumental extractions are used to manage dystocia cases, they are associated with a higher rate of neonatal lesions than spontaneous low births. Indeed, according to the literature, neonatal morbidity after extraction by vacuum is stable. Nevertheless, the frequency of the different types of complications varies according to the authors [3] [6] [11] [18] [19] [20].

By cons, Baume S. in France [21], had found 8.2\% cephalhematoma, but that term was attributed improperly to pathology observed in the delivery room a few hours after birth or in the first review of the infant to dayl. Moreover, it was no longer mentioned in the review of output day5, which we can assume that they were caput succedaneum early onset and disappearing in a few days.

\section{Conclusion}

Well used, the obstetrical vacuum remains a saving instrument. This requires a strict observance of the indications and a perfect knowledge of obstetrical mechanics. Large-scale mastery and extension could not only reduce the number of obstetric emergencies evacuations to referral centers, but also the number of abusive caesarean sections.

\section{References}

[1] Schaal, J.P., Equy, V. and Hoffman, P. (2008) Comparison Suction Cup Forceps. Journal de Gynécologie Obstétrique et Biologie de la Reproduction, 37, 231-243. https://doi.org/10.1016/S0368-2315(08)74761-6

[2] Benifla, J.L., Madelenat, P., Batallan, A., Carrasset, G., Fritel, X. and Demaria, F. (2006) Does Instrumental Extraction Cause Specific Lesions Depending on the Instrument (Forceps, Suction Cup, Spatulas). JTAs. http://www.lesjta.com 
[3] Cisse, C.T., Niang, M.M. and Diouf, A.B. (2015) Indications and Prognosis of Instrumental Fetal Extractions. African Journal of Surgery, 3, 186-191.

[4] Mutombo, K.L., Thanga, M.M., Mbuyamba, K.A., Luboya, N.O., Ngeleka, M.A., Mutombo, D.A.J., et al. (2014) Suction-Born Newborn at the Bonzola Maternity Hospital: Epidemiological Aspects and Evolution of 120 Cases. Pediatric Journal of the Congo River, 1, 4-10.

[5] Nolens, B., Lule, J., Namiiro, F., Roosmalen, J.V. and Byamugisha, J. (2016) Audit of a Program to Increase the Use of Vacuum Extraction in Mulago Hospital, Uganda. BMC Pregnancy and Childbirth, 16, 1-8. https://doi.org/10.1186/s12884-016-1052-3

[6] Randriambololona, D.M.A., Randriamahavonjy, R., Ramaholiarisoa, S.C., Randriambelomanana, J.A. and Andrianampanalinarivo, R.H. (2015) Maternal-Fetal Complications of Forceps Extractions and Vacuum Sucker. JMGO, 1, 7-11.

[7] Institute of Health Sciences Research: Needs Assessment in Obstetric and Neonatal Emergency Care, Coupled with the Mapping of Reproductive Health Care Supply in Burkina Faso, 2011, 181.

[8] Raynal, P., Bossard, A.E. and Carles, G. (2002) The Trial Engagement Suction Cup. Series of 50 Cases in French Guiana. Gynécologie Obstétrique \& Fertilité, 30, 765 771. https://doi.org/10.1016/S1297-9589(02)00448-4

[9] Dupuis, O., Silveira, R., Redarce, T., Dittman, A. and Rudigoz, R.C. (2003) Instrumental Extraction in 2002 in the AURORE Network: Serious Neonatal Incidence and Complication. Gynécologie Obstétrique \& Fertilité, 31, 920-926. https://doi.org/10.1016/j.gyobfe.2003.09.007

[10] Boni, S., Abauleth, R., Gondo, D., Koffi, A., Effoh, D. and Kone, N. (2005) Indications of Instrumental Extractions and Fetal and Maternal Prognosis at the $\mathrm{CHU}$ of Cocody. Journal of SAGO, 6, 1-5.

[11] Ouattara, S., Somé, A.D., Toure, B., Bambara, M. and Dao, B. (2012) Becoming Maternal-Fetal after Application of Vacuum Suction Cup at the University Hospital Center of Bobo Dioulasso, Burkina Faso. Clinics in Mother and Child Health, 9, 3 p.

[12] Traore, M., Traore, T.I., Traoré, D., Mounkoro, N., Sissoko, A., Diallo, A., Egah, K., Djiré, M.Y., Dolo, T. and Dolo, A. (2008) Clinical Aspects and Prognosis of Vacuum Deliveries at CHU Gabriel Touré. Journal of SAGO, 9, 11-15.

[13] Traore, B., Thera, T.A., Kokaina, C., Mounkoro, N., Teguete, I., Traore, Y., et al. (2010) Instrumental Extractions at the Maternity Ward of the Ségou CHR in Mali. Retrospective Study over 12 Months about 87 Cases. Med Black Afr, 57, 71-76.

[14] Grisot, C., Mancini, J., Troyer, J., Rua, S., Boubli, L., Ercole, C. and Carcopino, X. (2011) Perineal Morbidity of Instrumental Extractions by Spatulas and Suckers: What Is It Really? Journal de Gynécologie Obstétrique et Biologie de la Reproduction, 40, 348-358. https://doi.org/10.1016/j.jgyn.2011.03.007

[15] Earn, A.A., et al. (1967) An Appraisal of Malmstrôm's Vacuum Tractor (Vacuum Extractor). Obstetric and Paediatric Results. American Journal of Obstetrics \& Gynecology, 99, 732-743. https://doi.org/10.1016/0002-9378(67)90423-1

[16] Pambou, O., Wurch, T.H., Weygandt, J.M. and Treisser, A. (1991) Fetal Extraction Instrument Adapted in the Under-Equipped Countries, the Vacuum Sucker: Results of 393 Cupping at the Maternity of Selasta. Journal de Gynécologie Obstétrique et Biologie de la Reproduction, 123-129.

[17] Roszkowkki, I., Borkowski, R. and Kretowiez, J. (1963) Use of the Vacuum Extractor in Feta 1 Distress. American Journal of Obstetrics \& Gynecology, 87, 253-257. https://doi.org/10.1016/0002-9378(63)90507-6

[18] Baud, O. (2008) Neonatal Complications of Instrumental Extractions. Journal de 
Gynécologie Obstétrique et Biologie de la Reproduction, 37, 260-268. https://doi.org/10.1016/S0368-2315(08)74763-X

[19] Aouar, Z., Ramanah, R., Mangin, M., Leung, F., Mulin, B., Courtois, L., Cossa, S., Mallet, R. and Riethmuller, D. (2009) Maternal-Fetal Morbidity Related to Teissier Spatula Extraction. Comparative Study with the Minicup Type Vacuum Extraction Device. Journal de Gynécologie Obstétrique et Biologie de la Reproduction, 38, 642 647. https://doi.org/10.1016/j.jgyn.2009.08.006

[20] Vanlieferinghen, S., Girard, G. and Mandelbrot, L. (2009) Comparative Study of the Immediate Maternal-Fetal Morbidity of Extractions by Thierry's Spatulas and Suction Cups. Journal de Gynécologie Obstétrique et Biologie de la Reproduction, 38, 648-654. https://doi.org/10.1016/j.jgyn.2009.09.015

[21] Baume, S., Cheret, A., Creveuil, C., Vardon, D., Herlicoviez, M. and Dreyfus, M. (2004) Complications des accouchements assistés par ventouse Complications of vacuum extractor deliveries. Journal de Gynécologie Obstétrique et Biologie de la Reproduction, 33, 304-311. https://doi.org/10.1016/S0368-2315(04)96459-9 